\title{
BACTERIOLOGY OF FRESH WATER
}

\section{THE TYPES OF BACTERIA PRESENT IN LAKES AND STREAMS AND THEIR RELATIONSHIP TO THE BACTERIAL FLORA OF SOIL}

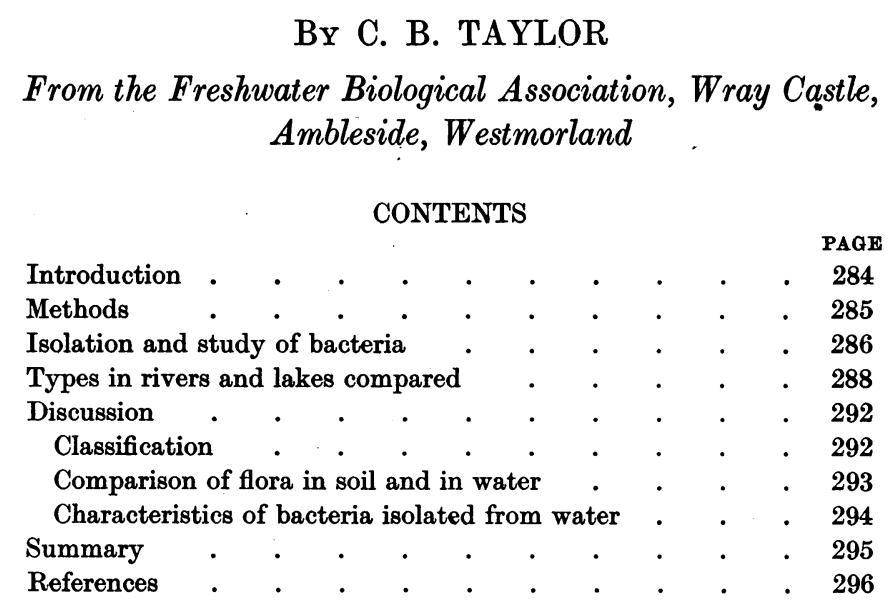

\section{INTRODUCTION}

VERY little work has been carried out since the beginning of the present century on the types of bacteria found in water, other than those representative of faecal pollution. Such published results as are available are mainly concerned with bacteria in rivers subject to pollution.

The first intensive study was that of Ward (1897) who obtained a number of cultures from the water of the River Thames. Discarding duplicates, eighty forms were isolated and cultivated and placed in twenty-two groups. Classification was made almost entirely on pigmentation, gelatin liquefąction, and capsulation. Cocci were differentiated from the other morphological forms. From the large number of groups formed, Ward concluded that the activities of most water bacteria had become weakened and that many variants of the same species were present. Fuller \& Johnson (1899) isolated a number of cultures from the water of the Ohio River at Cincinnati and elaborated a system of classification. They divided the cultures into two broad groups, the fluorescent and non-fluorescent types. The fluorescent types were then subdivided into chromogenic and non-chromogenic groups with the red, orange, yellow, and violet types each placed in a separate group irrespective of different shades of colour or different morphological and cultural characteristics. The non-chromogenic types were subdivided further according to their reactions in gelatin and carbohydrates, making in all thirteen groups. The authors claimed that the characteristics upon which the classification depended 
were quite fixed, a view not in agreement with that of Ward (1897). Boyce \& Hill (1900) amended the classification of Ward, and the 107 cultures studied by them were placed in twenty main groups, the members of four of which were thought to be merely varieties of one or two species with no real distinguishing characteristics. Pigmentation was used as the main method for classification.

The most detailed study is that of Jordan (1903), who isolated 543 cultures from the waters of the Illinois, Mississippi, and Missouri Rivers and classified them on the basis of their cultural, morphological, and biochemical features. This gave seventeen main groups with several subgroups based chiefly on colour.

On the bacterial flora of lakes there appear to be very few data. Lavanchy (1914), Grouitch (1918), and Marca (1927) published theses on the bacterial flora of Lake Geneva, but the numbers of organisms studied were small. Snow \& Fred (1926) examined cultures of bacteria isolated from Lake Mendota and claimed that they showed well-defined characteristics. Similar types were found to be present on different occasions at all depths and at all seasons. The majority grew slowly on ordinary laboratory media, did not ferment carbohydrates or curdle milk, but many liquefied gelatin. The chromogenic types represented a large proportion of the cultures and were studied in more detail. It was noted that white forms. were predominant and the authors pointed out that frequency of colours was similar to that found in the colours of flowers of plants.

\section{Methods}

The cultures studied in this report have all been isolated from samples of water from lakes or their inflows in the Lake District of north-west England. All these waters studied are subject to both animal and human pollution with the exception of Thirlmere, which is used as a source of water supply for the city of Manchester and is free of human pollution.

Samples of water were taken at different depths in the various lakes by means of the sampling device of Mortimer (1940), and from streams by means of a bottle clamped on the end of a pole. The samples were plated on sodium caseinate agar and incubated for 15 days at a temperatures of $20^{\circ} \mathrm{C}$., a procedure which has been found most suitable for the growth of the largest proportion of the bacteria present. It was found that direct inoculation of slopes of nutrient medium from colonies appearing on the plates resulted in a poor recovery, as a large proportion did not grow. Preliminary inoculation into soil extract, semi-solid medium proved to be no better and few cultures were capable of growth in either beef-peptone or meat-digest broth. It was found eventually that a suitable means of isolating the cultures was to inoculate tubes of semi-solid $(0.4 \%$ agar $)$ sodium caseinate medium and incubate for several days at $20^{\circ} \mathrm{C}$. After growth appeared in the tubes satisfactory inoculations could be made on to slopes of beef-peptone agar. This 
method was successful in isolating between 80 and $90 \%$ of the colonies picked off the plates. The slopes were incubated at $20^{\circ} \mathrm{C}$., and as soon as sufficient growth appeared Gram stains were made by the Kopeloff-Beerman modification. Because of the differences in growth rates of the various types, some showing good growth in $48 \mathrm{hr}$. and others poor growth even after 7 days, the cultures were not all examined after the same period of incubation. The characters of each culture were determined in various test media at $20^{\circ} \mathrm{C}$.

\section{ISOLATION AND STUDY OF BACTERIA}

Preliminary isolations were made from samples of water taken from depths of $1 \mathrm{~m}$. from the bottom and surface of Rydal Water, Esthwaite Water, Blelham Tarn, and the north and south basins of Windermere. At the time of sampling, the waters of all the lakes were stratified, and it was intended to determine whether any difference in flora existed in the hypolimnion and epilimnion. Inoculations at this time were made into either beef-peptone or meat-extract broths.

Even with the small number of characteristics employed the cultures fell into so many groups that it seemed preferable to record the percentage of the total number showing a positive or a negative result in the tests (Table 1).

From the relatively small number of cultures studied only certain limited conclusions can be drawn. The outstanding proportion of Gram-negative rods is significant; the proportions of other types were negligible. Spores were seen in only $6 \%$ of all the cultures. Biochemically the cultures showed little activity; gelatin was liquefied by $24 \%$, nitrates were reduced by $26 \%$, and acid and gas were formed from dextrose by only $5.6 \%$. Comparing the different lakes, considerable differences were found, especially regarding coloured colonies and nitrate-reducing and gelatin-liquefying types. The types from near the surface of the lakes were very similar to those from the bottom layer of water. The main difference was that the surface waters contained a larger proportion of chromogenic types.

A second series of isolations was made in January 1939 with the object of determining the types present before and after heavy rain. On 3 January the bacterial count in Windermere was only 850 per ml., but after a week of heavy rain ( 4.5 in.) it rose to 11,600 per ml. Approximately fifty colonies were isolated from plates poured on each occasion, half that number being obtained from samples at a depth of $10 \mathrm{~m}$. and half from the sample taken from water near the bottom of the lake. The water of the lake was in circulation at the time of collection of the samples.

The results shown in Table 2 may be compared with those obtained previously for Windermere north basin (Table 1). All the cultures isolated were rod forms, most of which were short rods and nearly $90 \%$ were Gram-negative. It cannot be said that the cultures obtained before and after rainfall showed essentially different characteristics in biochemical behaviour, for it may be 


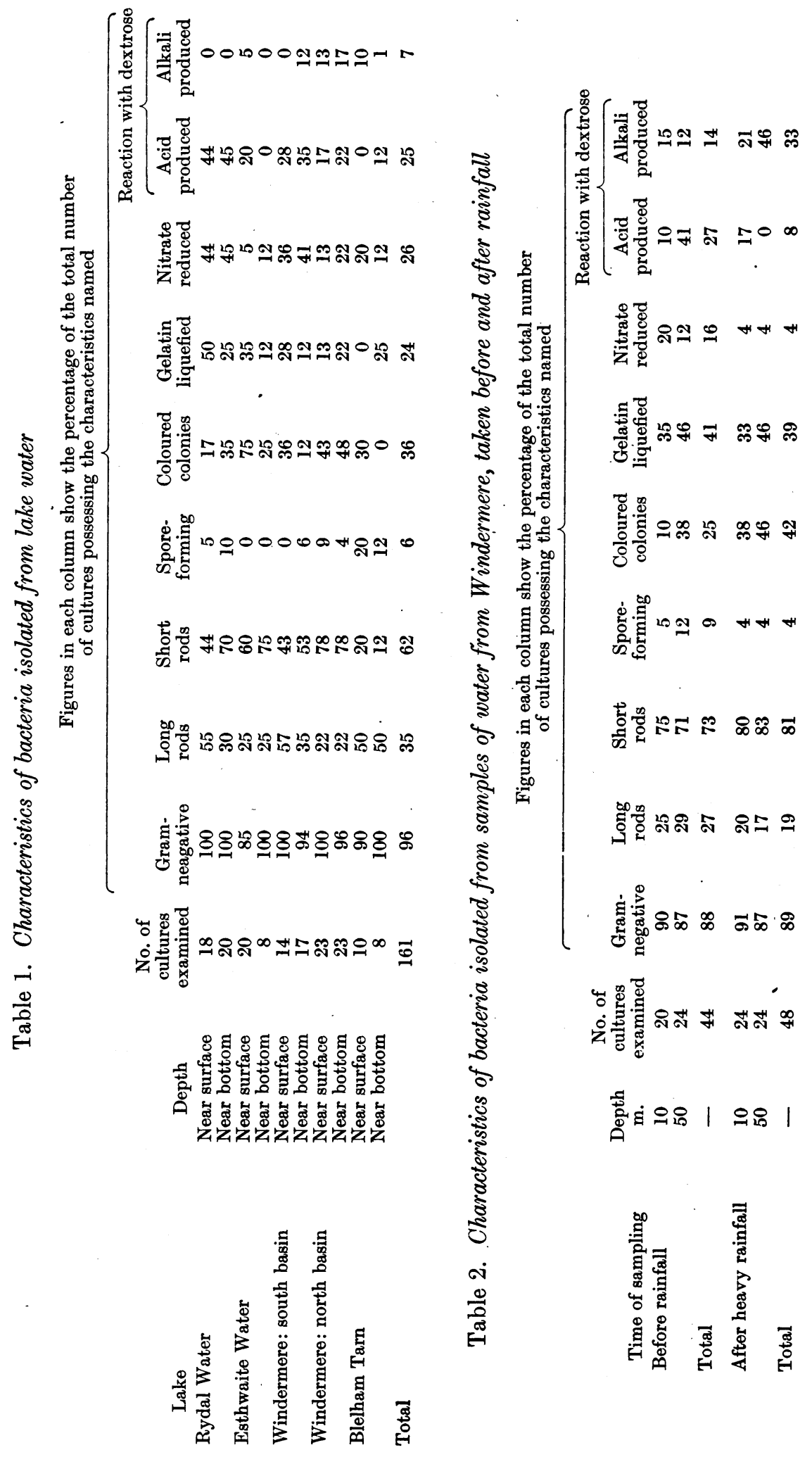


seen that cultures isolated from the two different depths of the lake on the same occasion often showed differences which were just as great. In the cultures isolated after rainfall, however, there appeared to be a larger percentage producing alkali from dextrose and a smaller percentage of cultures reducing nitrates than in the case of cultures isolated before rainfall. The absence of an increase in Gram-positive or spore-forming types is of great interest, as it suggests that there was little or no soil pollution caused by the heavy rain.

It was realized that in order to find any definite difference in the types in different samples of water a much larger number of colonies should be isolated for study. 167 cultures were isolated from the surface and bottom waters of Thirlmere. In addition to the tests used previously litmus milk was included as a test medium.

Table 3 shows results from the samples taken from the top and bottom waters of this relatively unpolluted lake. There is remarkably good agreement between the types in the surface and bottom samples, which was to be expected as the waters of the lake were in circulation at the time. Compared with Windermere (Table 2) there are no outstanding differences, but Thirlmere shows a higher ratio of long to short rods and has a greater proportion of coloured colonies and types producing acid from dextrose.

\section{TYPES IN RIVERS AND LAKES COMPARED}

In order to compare the types of bacteria in the lakes with those in the inflowing waters, samples were taken from near the surface and bottom of Windermere and Thirlmere and from two of the inflows of each lake. At the time of sampling the waters of both lakes were stratified. In this experiment the colonies were inoculated into semi-solid sodium caseinate agar in the usual manner and a very good recovery was obtained. Unfortunately, however, it was some weeks before the cultures could be dealt with, and it was found that a large proportion of those isolated from the surface of Windermere had died out; stained preparations made from the dead cultures showed that these organisms were similar in morphology.

Table 4 shows the main characteristics of the types isolated. Once again it was found that most of the cultures consisted of Gram-negative rod-shaped bacteria and that many were chromogenic. A comparison of the biochemical activities of the types isolated from different points shows that there were considerable differences between the cultures from the surface and bottom of each of the two lakes and also between the cultures from the various inflows. No striking difference is shown between the cultures from the water of Windermere and its inflows and those from the relatively unpolluted water of Thirlmere. A comparison of Table 4 with Tables 2 and 3 shows that some changes in types had occurred both in Windermere and in Thirlmere between the two occasions of sampling. 


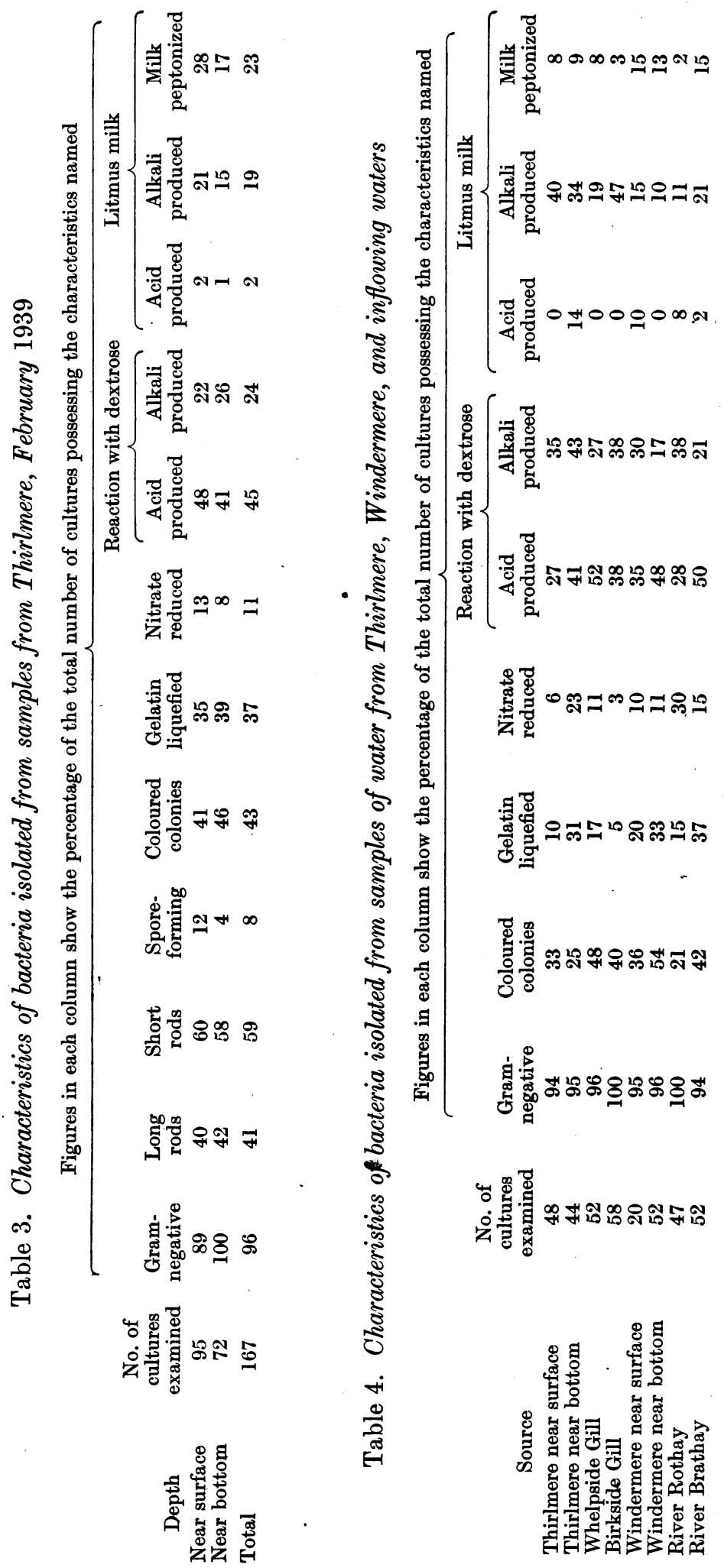


Eight predominant types isolated from the various samples are classified in Table 5. It can be seen that one type (no. 1) was particularly well distributed in Thirlmere and in the two inflowing streams. This type was easy to recognize by its moist viscous growth on agar and its long-banded rod-shaped cells. It was not found in Windermere waters and did not correspond to any cultures found previously in Thirlmere. Type 2 was mainly found in the inflows, only one culture being found in the lake. It was so prevalent in Whelpside Gill that it represented $42 \%$ of the total number isolated. This organism was a short motile rod characterized by the formation of a buttercupyellow pigment on agar and the production of an acid reaction in dextrose broth. The third and fourth types were confined respectively to the surface and bottom layers of the lake. The third type produced a characteristic red pigment on agar and gave negative results in all the tests; the fourth type was a vibrio, which produced a blackening of the agar medium. The different strains of this vibrio reacted somewhat differently to gelatin and milk.

Of the cultures from Windermere no particular type was found to be common either to both inflows or to both depths in the lake. In the surface sample twenty-nine out of the forty-nine cultures which grew in the semisolid medium died out before subculture; from the morphology and type of growth in the medium they appeared to be similar (no. 5). This type was not found elsewhere. One type (no. 6), which was confined to the bottom waters, appeared fourteen times $(27 \%)$. This organism, which gave no positive results to any of the tests, was a distinctive sausage-shaped, Gram-negative rod. Type 7, which was isolated from the River Brathay and from the lower water of the lake, was of a red-brown colour. Four of the six cultures of type $7^{\circ}$ obtained from the lake water differed from the rest by not liquefying gelatin and by peptonizing milk. The last type was a nitrate-reducing rod-shaped bacterium of which five cultures were isolated from the River Rothay and two from the bottom waters of the lake.

In comparing the inflows of the two lakes it is clear that in the pure streams of Thirlmere there are considerably fewer types than in the polluted rivers Rothay and Brathay. Thus $50 \%$ of the cultures from Whelpside Gill and $30 \%$ from Birkside Gill belong to types 1 and 2. In the River Rothay only five cultures (10\%), and in the case of the River Brathay only four (8\%) belonged to one type. In Windermere the prevalence of types 5 and 6 and their absence in the inflows suggest that these forms may be truly indigenous to lake water.

The characteristics of these eight types were found to be different from those of types isolated on previous occasions from Thirlmere and Windermere, which suggests that the flora changes considerably from time to time. Further study of the eight types was made more difficult by the fact that after a few subcultures the organisms tended to die out and types 1 and 4 were lost. It has been found impossible to identify any of the above-mentioned types with those described by Bergey (1939), though certain resemblances could be found. Some of the more physiologically active types which have appeared 


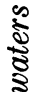

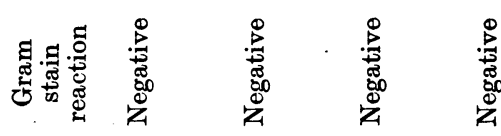

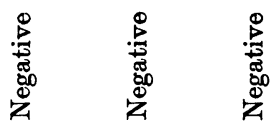

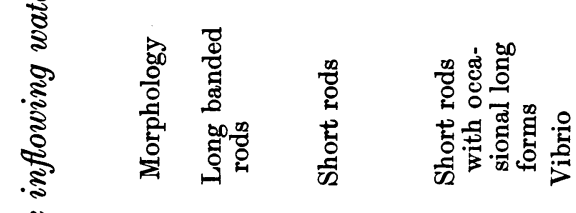

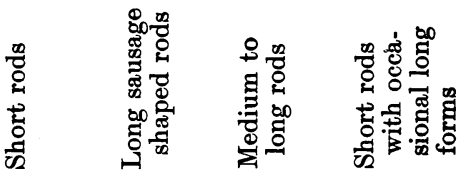

ฐ

胥

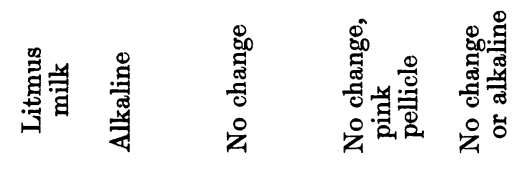

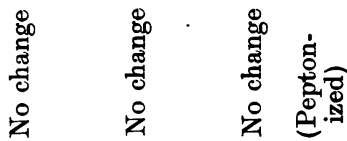

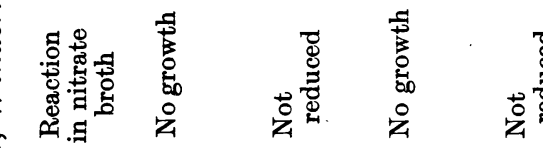

है

突营

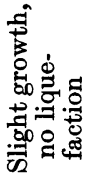

兽:

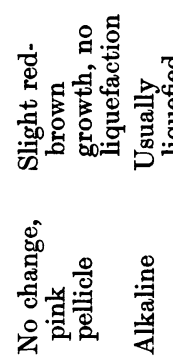

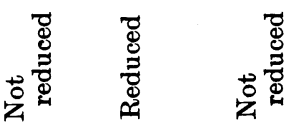

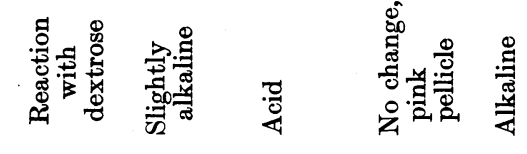

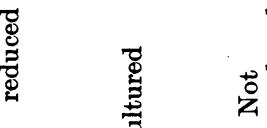

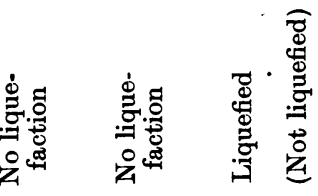

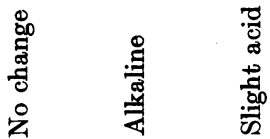

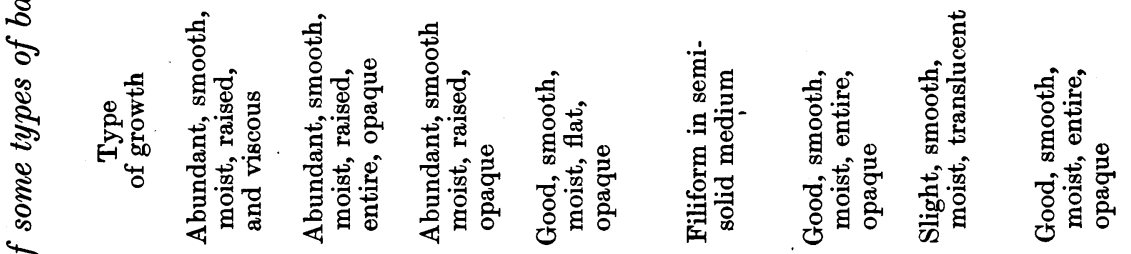

b

离 焉

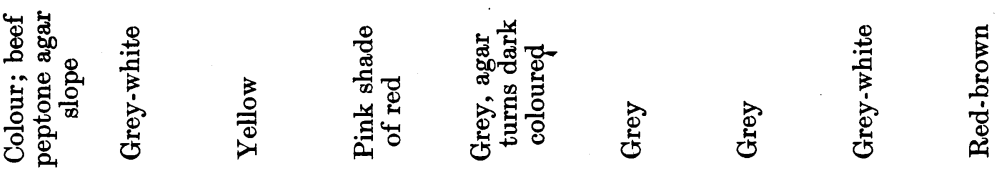

है है

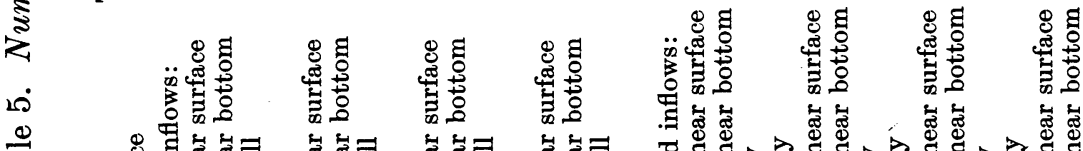

要 D.
D. 
in smaller numbers have been easier to classify, particularly the fluorescent bacteria, though many of them were apparently unrecorded species or strains.

\section{Discussion}

\section{Classification}

A limited study of nearly 800 cultures of bacteria obtained from lakes and streams has brought out several well-defined points. The types present are almost invariably rod-shaped and Gram-negative, and a large proportion are chromogenic. Coccus forms are relatively rare and spore-formers do not ordinarily make up more than $10 \%$ of the total. A striking feature of these bacteria found in water is the marked lack of biochemical activities which made it difficult to assign characteristics for purposes of classification. A considerable number of those isolated formed pin-point colonies on sodium caseinate agar and after subculture grew poorly on the ordinary laboratory media; others which at first grew well died off after a few subcultures.

One of the difficulties of the work has been to decide upon suitable differential tests. In dextrose broth some cultures failed to grow despite repeated inoculations, and with other cultures the amount of acid or alkali produced was slight; it is significant that of all the cultures examined only nine, all from the first series of isolations, were able to ferment dextrose with the production of acid and gas. Some cultures did not grow in nitrate broth nor in a synthetic nitrate medium. Reactions in litmus milk were varied and weak. The only characteristics which appeared to be of real value were the colours produced on solid media and the liquefaction of gelatin. There were many shades of yellow and red, and it is probable that colour may be lost, gained, or modified; but in general it was found that cultures of the same colour shade and type of growth were usually replicates. The Gram stain was valuable in showing the absence of positive or positive-negative types.

It appears certain that the majority of bacteria found in water cannot be adequately classified by the old biochemical tests, and in view of similar findings by workers with soil bacteria it seems that this applies to a large proportion of all bacteria found in nature except those which develop best at body temperature. Lochhead \& Taylor (1938) came to the conclusion that soil organisms in general, being physiologically unstable, show adaptability to changing conditions and are thus difficult to classify on a physiological basis. Conn et al. (1940) have endorsed this view and consider that progress in classification may be made more adequately by a study of the Gram reaction, type of flagellation, and tendency to show true or false branching or irregularities in shape of cells. Such points should give a basis for classification, but it is desirable that the characteristic functions of organisms should be taken into consideration for the role of most of the indigenous bacteria in soil or in water still remains to be solved. 


\section{Comparison of flora in soil and in water}

It is important to compare the characteristics of the predominant microflora in water and in soil, particularly as it is still asserted by some workers that water contains no specific bacterial flora but merely the residue of organisms washed in from other habitats. In Table 6 the main groups of bacteria found in the lakes and streams examined are compared with the main groups of bacteria in soil reported by Taylor \& Lochhead (1938) and Topping (1937). Taylor \& Lochhead studied the morphology and reactions of 625 cultures isolated from soil plots which had received yearly doses of farmyard manure or artificial manure, or had received no treatment. The cultures were classified in eight morphological groups. Topping (1937) isolated 209 cultures

- Table 6. Comparison of the main morphological groups of bacteria in soil and water

\begin{tabular}{|c|c|c|}
\hline Group & Soil (after Taylor \& Lochhead, 1938) (625 cultures) & $\%$ of total \\
\hline $\begin{array}{l}\text { I } \\
\text { IV } \\
\text { V } \\
\text { II } \\
\text { III } \\
\text { VI } \\
\text { VII } \\
\text { VIII }\end{array}$ & $\begin{array}{l}\text { Short rods, Gram-positive } \\
\text { Short rods, changing to cocei (Bact. globiforme group) } \\
\text { Coccoid rods, Gram-positive } \\
\text { Short rods, Gram-negative } \\
\text { Short rods, Gram-variable } \\
\text { Cocci, Gram-positive or negative } \\
\text { Long rods, non-spore-forming } \\
\text { Spore-forming rods }\end{array}$ & $\begin{array}{r}27 \cdot 6 \\
9 \cdot 1 \\
6 \cdot 0 \\
36 \cdot 1 \\
9 \cdot 4 \\
3 \cdot 4 \\
3 \cdot 8 \\
3 \cdot 8 \\
3 \cdot 8\end{array}$ \\
\hline \multicolumn{3}{|c|}{ Soil (after Topping, 1937) (209 cultures) } \\
\hline $\begin{array}{l}1 \\
2 a \\
2 b \\
3\end{array}$ & $\begin{array}{l}\text { Gram-positive motile bacteria which may produce branching variants } \\
\text { Gram-positive non-motile rod-shaped bacteria } \\
\text { Gram-positive non-motile mycelium-forming bacteria } \\
\text { Gram-negative bacteria (motile and non-motile) }\end{array}$ & $\left.\begin{array}{l}23 \cdot 0 \\
31 \cdot 1 \\
19 \cdot 0 \\
26 \cdot 7\end{array}\right\} 73 \cdot 1$ \\
\hline \multicolumn{3}{|c|}{ Water (671 cultures) } \\
\hline & $\begin{array}{l}\text { Gram-negative rod-shaped bacteria } \\
\text { Gram-positive rod-shaped bacteria } \\
\text { Cocci }\end{array}$ & $\begin{array}{r}95 \cdot 5 \\
3 \cdot 8 \\
0 \cdot 7\end{array}$ \\
\hline
\end{tabular}

from twenty soils from Scotland and Saxony. These cultures were obtained by the use of several different media and dilutions sufficiently high to reproduce only a few colonies and were thus considered to be the most prevalent types. Only four main morphological groups were recognized. Although the results from water are most satisfactorily compared with the work of Taylor \& Lochhead since similar methods were employed, the results of Topping confirm that Gram-positive types of bacteria are at least as numerous as Gram-negative types, and that in soils there exist groups of Gram-positive bacteria which are characterized by their ability to produce branching or mycelium-like forms or to change from rod to coccus shape. The first two types producing branching or mycelium-like forms have been considered by various workers to belong to the genera Mycobacterium and Corynebacterium, while the type exhibiting the peculiar change in morphology is still classified as Bact. globiforme Conn (Bergey, 1939); as, however, branching variants of the latter have been recorded (Taylor \& Lochhead, 1937) it appears to be closely 
allied to the other types. That such morphological groups are among the indigenous microflora of soil was shown by Taylor (1938), who found Bact. globiforme in 99 out of 100 soils of many different agricultural types collected from widely separated points in Canada.

A comparison of the soil and water bacteria (Table 6) shows the marked difference between the two habitats in that the Gram-positive types in water are insignificant in comparison with those found in soil, and that none of Topping's groups $1,2 a$, or $2 b$ or the Bact. globiforme Conn group of Taylor \& Lochhead (1938) was found. Of the twenty-six $(3.8 \%)$ cultures from water which were Gram-positive five were identical in description with Topping's strain 173, group $2 a$, and the remaining twenty-one were heterogeneous in character. Only five cultures $(0.7 \%)$ of cocci were isolated.

It is of interest to compare the Gram-negative forms found in water with those in soil. Topping considered that no single type was predominant and made no detailed report. She mentions, however, that in the main these organisms were chromogenic and biochemically inactive; sixteen strains were identical with or closely related to Flavobacterium fecale (Bergey, 1939) and eight strains were similar to Flavobacterium ochraceum (Bergey, 1939). Taylor \& Lochhead (1938) found that the Gram-negative group was the least active physiologically of all groups and was suppressed to the greatest extent by the addition - of dextrose to soil extract, $20 \%$ of the cultures being inhibited by dextrose in a concentration of $1 \%$.

\section{Characteristics of bacteria isolated from water}

The main features of the bacteria isolated from water were the outstanding proportion of rod forms, in particular Gram-negative rods, and the absence of Gram-positive pleomorphic rods which are characteristic 'of soil. The majority of organisms grew slowly in ordinary laboratory media and did not ferment carbohydrates nor curdle milk, but gelatin liquefaction was common and a large number of cultures were chromogenic. In these respects the results confirm those of Snow \& Fred (1926), but there are two points on which they differ. First, it is not considered that characteristics of the organisms are well defined, and secondly, that the types present in lakes are not the same at all times of the year or at all depths. Slight differences found either in morphology or in biochemical activity in strains of obviously the same type are in agreement with the statement of Ward in 1897 that many variants of the same species may be present, but as this is the case in habitats other than water it seems doubtful whether it is a result of attenuation caused by long immersion. When the cultures isolated from lakes are grouped on the basis of their biochemical activities, it is true that no outstanding differences are observed between samples taken at different times of the year, but the most prevalent types at those times are different. It seems reasonable to suppose that, as in soil, a delicate balance exists between the types present in water and that the balance may be easily altered by changes in temperature and in 
the available nutrient material released by decomposition of organic matter. To what extent the bacteria washed in from outside a lake may multiply therein is not yet clear, but it seems certain that some at least of the types found in lakes are capable of multiplication in lake water and are commonly distributed elsewhere.

In conclusion it is emphasized that the usual methods of classification can serve little purpose in the bacteriology of water, except in the study of pathogens or of the problems of pollution. The organisms can usually be separated only into groups on the basis of their morphology and physiology. The work reported in this paper serves to substantiate some previous work, and in particular to show the main differences in the bacterial flora of water and soil.

\section{SUMMARY}

1. Approximately 800 cultures of bacteria have been isolated from samples of water taken from lakes and from some of their inflowing waters. The morphology and Gram-staining reaction of the cultures have been determined together with the reactions in nutrient gelatin, dextrose broth, nitrate broth, and litmus milk.

2. Many organisms grew poorly on artificial media, and were unable to grow in either dextrose or nitrate broth. In general the cultures showed weak physiological activity, particularly in litmus milk and in dextrose, though gelatin liquefaction was fairly common. Colonies produced on solid media were frequently pigmented, shades of yellow being particularly common. A significant feature was that most of the bacteria $(95 \%)$ were rod-shaped, and though many cultures showed considerable variation in cell length and were consequently difficult to classify, short rods were in general more prevalent than long. Coccus forms made up less than $1 \%$ of the toal number considered.

3. When the cultures were grouped according to their biochemical activities no consistent differences were observed between the types from near the surface and from near the bottom of a lake, nor between the lake and the inflow, but differences were observed in samples taken from the same lake on different occasions. Some types were common to both the lake and the inflows, while others occurred in only one of those habitats. Some types were found both near the surface of the lake and near the bottom, whilst others were confined to one depth.

4. A comparison of the types of bacteria isolated from waters with those found by other workers in soils shows that the main difference in the bacterial flora is the absence in water of the Gram-positive pleomorphic forms of the genera Mycobacterium and Corynebacterium and of Bact. globiforme Conn., all of which are common in soils of very widely different agricultural types.

5. In the discussion it is pointed out that, in common with soil types bacteria isolated from water cannot be adequately classified by the usual tests 
in carbohydrates; in dextrose broth, for instance, the reaction is often only a slight change in $p \mathrm{H}$ value.

The investigation described in this paper was carried out by the Freshwater Biological Association, as part of the programme of the Water Pollution Research Board of the Department of Scientific and Industrial Research. The paper is published by permission of the Department.

\section{REFERENCES}

Bergey, D. H. (1939). Manual of Determinative Bacteriology, 5th ed. Baltimore: The Williams and Wilkins Co.

Boyce, R. W. \& HiLl, C. A. (1900). A classification of micro-organisms found in water. J. Path. Bact. 6, 32.

Conn, H. J., Wolfe, G. E. \& Ford, M. (1940). Taxonomic relationships of Alcaligenes spp. to certain soil saphrophytes and plant parasites. J. Bact. 39, 207.

Fuller, G. W. \& JoHnson, G. A. (1899). On the differentiation and classification of water bacteria. J. Exp. Med. 4, 609.

Groortch (1918). Contribution à l'étude de la flore bactérienne du lac de Genève. Thesis, Institute of Botany of Geneva.

JordaN, E. O. (1903). The kinds of bacteria found in river water. J. Hyg., Camb., 3, 1.

Lavanchy, C. J. (1914). Contribution à l'étude de la flore bactérienne du lac de Genève. Thesis, Institute of Botany of Geneva.

LOCHHEAD, A. G. \& TAYLOR, C. B. (1938). Qualitative studies of micro-organisms. I. General introduction. Can. J. Res. C, 16, 152.

Marca, A. A. (1927). Contribution à l'étude de la flore bactérienne du lac de Genève. Thesis, Institute of Botany of Geneva.

Mortimer, C. H. (1940). An apparatus for obtaining water from different depths for bacteriological examination. J. Hyg., Camb., 40,641.

SNow, L. M. \& Fred, E. B. (1926). Some characteristics of the bacteria of Lake Mendota. Trans. Wis. Acad. Sci. Arts Lett. 22, 143.

TAYLOR, C. B. (1938). Further studies of Bacterium globiforme and the incidence of this type of organism in Canadian soils. Soil Sci. 46, 307.

TAYLOR, C. B. \& LOChHEAD, A. G. (1937). A study of Bacterium globiforme in soils differing in fertility. Can. J. Res. C, 15, 340.

TAYLOR, C. B. \& LoCHHEAD, A. G. (1938). Qualitative studies of soil micro-organisms. II. A survey of the bacterial flora of soils differing in fertility. Can.J. Res. C, 16, 162.

Topping, L. E. (1937). The predominant micro-organisms in soils. I. Description and classification of the organisms. Zbl. Bakt. Abt. 2, 97, 289.

WARD, H. M. (1897). Bacterial flora of the River Thames. Abstract from the fifth report to the Royal Society Water Research Committee, Proc. Roy. Soc. 61, 415.

(MS. received for publication 27. II. 42.-Ed.) 